\title{
Pemanfaatan Vinasse sebagai Pupuk Organik Cair untuk Meningkatkan Pertumbuhan dan Hasil Bunga Kol (Brassica oleracea var. Botrytis L.)
}

\section{Utilization of Vinasse as Liquid Organic Fertilizer to Increase Cauliflower (Brassica oleracea var. Botrytis L.) Growth and Yield}

\section{Siti Ma'rufah', Riza Yuli Rusdiana², dan Vega Kartika Sari ${ }^{3 *}$}

1 Jurusan Produksi Pertanian, Politeknik Negeri Jember

${ }^{2,3}$ Program Studi Agronomi, Fakultas Pertanian, Universitas Jember

*E-mail : vegakartikas@unej.ac.id

\begin{abstract}
Cauliflower is an annual vegetable crop that is rich in vitamins and minerals. This is one of the commodities exported by Indonesia. Fertilization is a determinant of the success of vegetable farming. The use of chemical fertilizers that are not balanced with organic fertilizers can have a negative impact on the environment. Vinasse is an industrial waste that is rich in organic matter, potassium, calcium, and micronutrients and can be used as liquid organic fertilizer. This study aims to determine the effect of giving several doses of vinasse on the growth and production of cauliflower. The experimental design used is a single factor Randomized Block Design (RCBD). The treatment dose used consisted of four levels namely, Ol/ha (V0), $15000 \mathrm{l} / \mathrm{ha}$ (V1), $20000 \mathrm{l} / \mathrm{ha}(\mathrm{V2}), 25000 \mathrm{l} / \mathrm{ha}$ (V3). The results showed that there was a very significant effect on plant height at 14 DAP and 21 DAP, and on the variable of flower weight per sample, flower weight per bed, and fresh stover weight per sample, and showed a significant effect on the number of leaf variable on age 14 DAP and 21 DAP. The best treatment of vinasse fertilizer is $25000 \mathrm{l} / \mathrm{ha}(\mathrm{V} 3)$.
\end{abstract}

Keywords: cauliflower, liquid organic fertilizer, vinasse

Disubmit : 12 September 2019; Diterima: 10 November 2019; Disetujui : 7 Januari 2020

\section{PENDAHULUAN}

Bunga kol merupakan jenis sayuran dari famili Brassicaceae. Bagian yang dikonsumsi ialah massa bunga yang disebut dengan "Curd", umumnya berwarna putih hingga putih kekuningan. Massa bunga mengandung vitamin dan mineral yang sangat baik bagi tubuh, sehingga jenis sayuran ini digemari oleh masyarakat untuk campuran berbagai masakan. Produktivitas bunga kol tahun 2017 sebesar 10.79 ton/ha mengalami peningkatan dibandingkan 2 tahun sebelumnya (BPS, 2018). Bahkan bunga kol termasuk dari 17 komoditas sayuran semusim yang diekspor oleh Indonesia pada tahun 2018 (BPS, 2019). Peningkatan produksi bunga kol masih diiringi dengan penggunaan pupuk kimia yang terus-menerus, meski diketahui pengaruh pupuk kimia berefek negatif terhadap tanah, seperti turunnya kandungan bahan organik dan mikroorganisme tanah, tanah menjadi padat dan terjadi pencemaran lingkungan (Sulaeman et al., 2017) dan dapat berpengaruh pula terhadap kesehatan manusia. Selain pengaruh negatif dari penggunaan pupuk kimiawi, mahalnya harga membuat petani harus mengeluarkan banyak biaya untuk pemenuhan pemupukan. 
Pemupukan merupakan faktor penentu keberhasilan dalam budidaya sayuran. Kesadaran petani untuk dapat mengimbangi penggunaan pupuk kimia dengan pupuk organik harus terus diupayakan. Menurut Juhriah et al. (2018), pupuk organik dapat memberikan tambahan bahan organik, hara, memperbaiki sifat fisik tanah, serta mengembalikan hara yang terangkut oleh hasil panen. Pupuk organik cair (POC) adalah salah satu jenis pupuk yang mengandung unsur hara makro dan mikro yang cukup tinggi sebagai hasil senyawa organik bahan alami yang mengandung sel-sel hidup aktif dan aman terhadap lingkungan serta pemakainya (Wahyunindyawati et al., 2012). Satriawi et al. (2019) menambahkan, POC dapat berasal dari berbagai limbah organik. Limbah adalah bahan sisa yang dihasilkan dari kegiatan produksi baik skala rumah tangga, industri maupun pertambangan.

Vinasse merupakan limbah cair hasil pembuatan gula tebu yang berupa molasses, yang diproses menjadi etanol dan dari proses tersebut diperoleh produk sampingan berupa vinasse (Vyatrisa et al., 2017). Limbah vinasse bersifat asam ( $\mathrm{pH} 3-4$ ), sehingga dapat menimbulkan masalah jika langsung dibuang ke aliran sungai (Umami et al., 2014). Disamping itu, vinasse kaya akan bahan organik, kalium, dan kalsium serta mengandung unsur mikro, sehingga dapat dimanfaatkan sebagai pupuk organik cair (Sadewo, 2017). Berdasarkan hasil penelitian Sadewo (2017), pemberian vinasse (100\% vinasse) dengan dosis 12000L/ha mampu mensubstitusi unsur kalium yang berasal dari pupuk anorganik ( $200 \mathrm{~kg} \mathrm{KCl} / \mathrm{ha})$, namun tidak secara langsung dapat meningkatkan pertumbuhan tanaman tebu. Hasil penelitian Vyatrisa et al. (2017) menunjukkan bahwa penggunaan vinasse (25000 l/ha) dengan tanpa pemberian pupuk organik lainnya memberikan pertumbuhan dan hasil pak choi yang terbaik. Berdasarkan hal tersebut, penelitian ini dilakukan untuk mengetahui dosis vinasse yang sesuai untuk pertumbuhan dan produksi bunga kol (Brassica oleracea L.).

\section{METODE PENELITIAN}

Penelitian ini dilaksanakan pada bulan September 2018 hingga Desember 2018 di lahan percobaan daerah Tawangmangu Kabupaten Jember. Bahan yang digunakan adalah limbah cair vinasse, bibit bunga kol varietas PM 126 F1, EM-4, dolomit, bokashi kandang ayam 15 ton/ha, ZA, Urea, TSP, KCl (masing-masing $250 \mathrm{~kg} / \mathrm{ha}$ ), borax/borate 10-20 kg/ha, NPK Mutiara (1,5 g/ tanaman saat 14 HST dan $21 \mathrm{HST} ; 2 \mathrm{~g} /$ tanaman saat 28 HST dan 2,5g/tanaman saat 35 HST), dan mulsa hitam perak.

Penelitian ini dilakukan dua tahap, tahap pertama adalah pembuatan pupuk organik cair yaitu fermentasi vinasse (Gambar 1) dan tahap kedua adalah pelaksanaan aplikasi vinasse di lahan percobaan. Rancangan percobaan menggunakan Rancangan Acak Kelompok (RAK) faktor tunggal yaitu dosis vinasse sebagai faktor perlakuan. Taraf perlakuan terdiri dari V0, V1, V2, V3 dengan lima kali pengulangan, yaitu :

$\mathrm{V} 0=$ Tanpa vinasse 0 1/ha

$\mathrm{V} 1=$ Vinasse $15.000 \mathrm{l} / \mathrm{ha}$

$\mathrm{V} 2=$ Vinasse 20.000 1/ha

$\mathrm{V} 3=$ Vinasse $25.000 \mathrm{l} / \mathrm{ha}$

Variabel-variabel respon yang diamati meliputi pertumbuhan dan hasil bunga kol. Komponen pertumbuhan bunga kol yang diamati adalah tinggi tanaman $(\mathrm{cm})$ dan jumlah daun (helai), sedangkan komponen hasil bunga kol yang diamati adalah bobot segar bunga per tanaman (g) dan bobot segar brangkasan per tanaman (g). Pengamatan terhadap variabel respon pertumbuhan bunga kol dilakukan pada umur 14 HST, 21 HST, 28 HST dan 35 HST, sedangkan pengukuran variabel respon hasil tanaman bunga kol dilakukan setelah panen. Analisis data pada penelitian ini menggunakan analisis ragam (uji F), apabila antar perlakuan terjadi perbedaan yang signifikan maka dilakukan uji lanjut BNT taraf 5\%. 


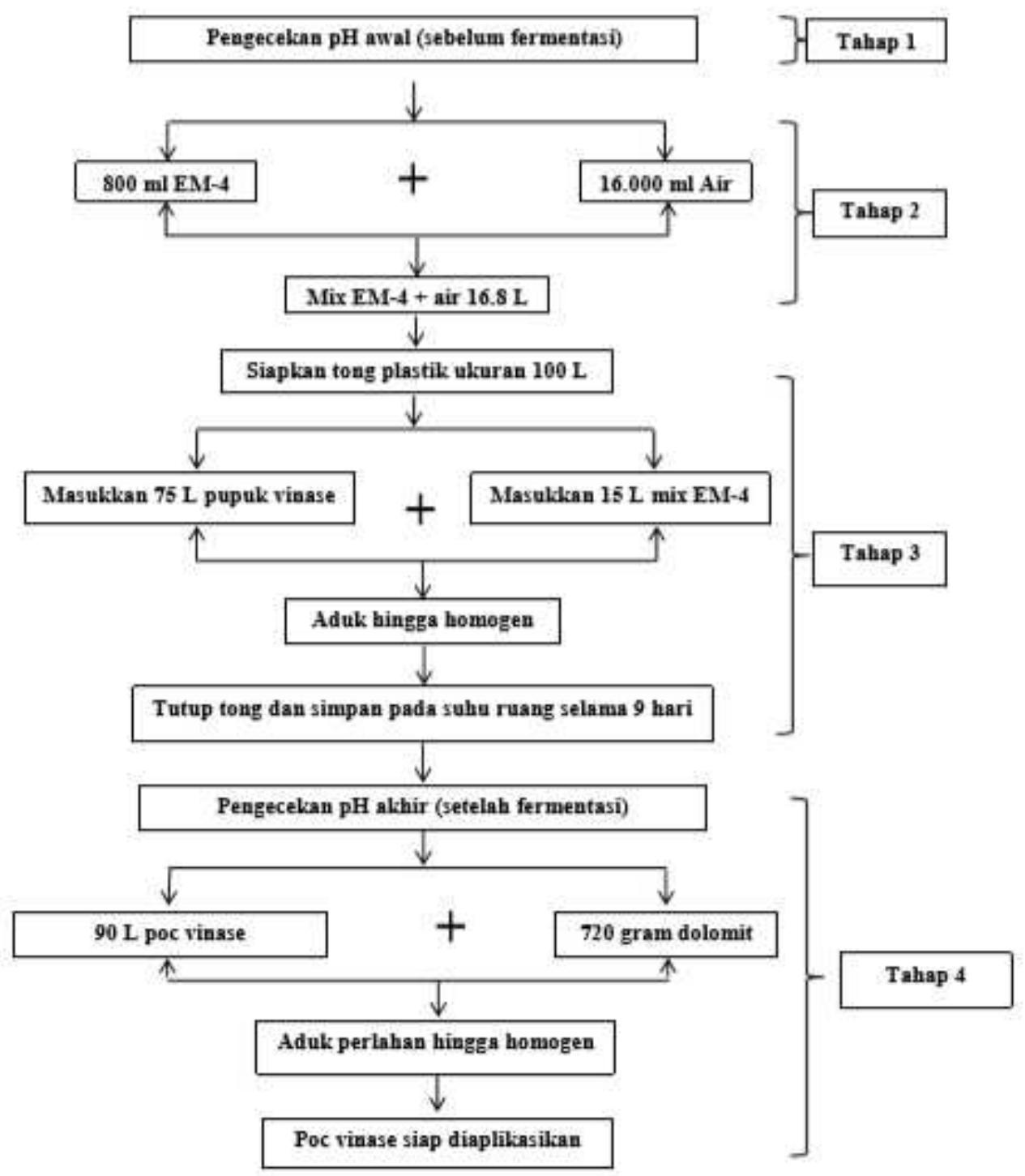

Gambar 1. Proses fermentasi vinasse hingga siap diaplikasikan

Berdasarkan gambar diatas, proses pengolahan fermentasi vinasse melalui beberapa tahapan. Tahap 1 melakukan pengecekan $\mathrm{pH}$ awal, dan menunjukkan $\mathrm{pH}$ sebesar 4,05. Menurut Maghfiroh et al., (2016), vinasse dengan $\mathrm{pH}$ berkisar 4,35 atau tergolong asam berbahaya untuk tanaman sehingga perlu dilakukan penaikan pH. Pada tahap 2 dilakukan penambahan mikroorganisme (EM-4) dan air (Qo'idah, 2015). Pada tahap selanjutnya yaitu proses fermentasi mengacu pada Lamuri et al., (2016) yaitu mencampur vinasse dan larutan EM-4 (5:1) disimpan pada suhu ruang selama 9 hari. Menurut Lamuri et al., (2016), adanya pengaruh waktu dan penambahan EM-4 terhadap peningkatan kadar N, P, dan K dalam proses fermentasi limbah bioethanol. Diperoleh kadar N, P, K tertinggi yaitu sebesar 0,4178\% (N);0,1782\% $\left(\mathrm{P}_{2} \mathrm{O}_{5}\right)$; dan 2,1636\% $\left(\mathrm{K}_{2} \mathrm{O}\right)$ pada fermentasi hari ke-9. Pada tahap terakhir dilakukan pengecekan $\mathrm{pH}$ vinasse, diperoleh $\mathrm{pH}$ sebesar 4,42 kemudian ditambahkan dolomit $8 \mathrm{~g} / \mathrm{l}$ vinasse dan $\mathrm{pH}$ menjadi 6,65.

\section{HASIL DAN PEMBAHASAN}

Pengaruh Dosis POC Vinase Terhadap Pertumbuhan Tanaman Bunga Kol. Hasil penelitian menunjukkan bahwa perlakuan POC vinasse terhadap tinggi tanaman berdasarkan hasil analisis sidik ragam menunjukkan bahwa perlakuan beberapa takaran vinase berpengaruh sangat nyata terhadap tinggi tanaman 
bunga kol (Brassica oleracea L. var. Botrytis Subvar. PM 126 F1) pada umur 14 dan 21 HST, sedangkan pada umur 28 dan 35 HST menunjukkan pengaruh yang tidak nyata. Hasil analisis disajikan pada Tabel 1.

Tabel 1. Rerata pengaruh pemberian POC vinasse terhadap tinggi tanaman bunga kol

\begin{tabular}{lcccc}
\hline \multirow{2}{*}{ Perlakuan } & \multicolumn{4}{c}{ Umur Tanaman } \\
\cline { 2 - 5 } & $14 \mathrm{HST}$ & $21 \mathrm{HST}$ & $28 \mathrm{HST}$ & $35 \mathrm{HST}$ \\
\hline V0 : Tanpa Vinasse 0 1/ha & $12,03 \mathrm{c}$ & $17,30 \mathrm{~d}$ & 26,15 & 36,85 \\
V1 : Vinasse 15.000 1/ha & $13,17 \mathrm{~b}$ & $17,93 \mathrm{c}$ & 25,63 & 35,77 \\
V2 : Vinasse 20.000 1/ha & $13,73 \mathrm{ab}$ & $19,40 \mathrm{~b}$ & 26,40 & 37,37 \\
V3 : Vinasse 25.000 1/ha & $15,55 \mathrm{a}$ & $21,03 \mathrm{a}$ & 28,03 & 40,08 \\
\hline
\end{tabular}

Keterangan : Angka yang diikuti huruf yang berbeda pada kolom yang sama menunjukkan berbeda nyata menurut Uji BNT pada taraf 5\%

Berdasarkan hasil tersebut dapat diketahui bahwa perlakuan pemberian dosis vinasse 25.000 l/ha (V3) memberikan hasil terbaik pada setiap umur pengamatan. Hal tersebut sesuai dengan hasil penelitian Umami et al. (2014) menyatakan bahwa pemberian pupuk organik cair vinasse dapat meningkatkan tinggi tanaman kangkung darat. Selaras dengan hasil penelitian Hosiholan et al. (2017) tentang pengaruh perbedaan dosis limbah cair bioethanol (vinasse) terfermentasi terhadap pertumbuhan tanaman bibit kakao (Theobroma cacao L.) menyatakan bahwa pemberian limbah cair bioethanol telah mampu memenuhi kebutuhan hara $\mathrm{N}, \mathrm{P}$ dan $\mathrm{K}$ bagi bibit kakao sehingga memberikan hasil rerata tinggi bibit yang baik. Hal ini dikarenakan pemberian pupuk vinasse berfungsi menambah ketersediaan hara pada tanah yang dibutuhkan oleh tanaman, sehingga sangat berperan dalam pertumbuhan vegetatif tanaman (Dewi dan Simanjuntak, 2015).

Hasil analisis perlakuan POC vinasse terhadap jumlah daun disajikan pada Tabel 2. Berdasarkan hasil sidik ragam menunjukkan bahwa perlakuan beberapa takaran vinasse berpengaruh nyata terhadap jumlah daun bunga kol pada umur 14 dan 21 HST, sedangkan pada umur 28 dan 35 HST menunjukkan pengaruh yang tidak nyata.

Tabel 2. Rerata pengaruh pemberian POC vinasse terhadap jumlah daun bunga kol

\begin{tabular}{lcccc}
\hline \multirow{2}{*}{ Perlakuan } & \multicolumn{4}{c}{ Umur Tanaman } \\
\cline { 2 - 5 } & $14 \mathrm{HST}$ & $21 \mathrm{HST}$ & $28 \mathrm{HST}$ & $35 \mathrm{HST}$ \\
\hline V0 : Tanpa Vinase 0 1/ha & $5,27 \mathrm{c}$ & $9,13 \mathrm{~b}$ & 13,27 & 17,33 \\
V1 : Vinase 15.000 1/ha & $5,63 \mathrm{~b}$ & $9,42 \mathrm{~b}$ & 13,10 & 17,20 \\
V2 : Vinase 20.000 1/ha & $6,03 \mathrm{ab}$ & $9,13 \mathrm{~b}$ & 13,77 & 17,83 \\
V3 : Vinase 25.000 1/ha & $6,47 \mathrm{a}$ & $10,97 \mathrm{a}$ & 14,07 & 18,63 \\
\hline
\end{tabular}

Keterangan : Angka yang diikuti huruf yang berbeda pada kolom yang sama menunjukkan berbeda nyata menurut Uji BNT pada taraf 5\%.

Perlakuan pemberian dosis vinasse 25.000 1/ha (V3) memberikan hasil terbaik pada setiap umur pengamatan. Berdasarkan hasil penelitian Vyatrisa et al. (2017) tentang pengaruh vinasse dan macam pupuk organik terhadap pertumbuhan dan hasil pak choi menyatakan bahwa penggunaan pupuk vinasse 25.000 1/ha memberikan hasil rerata jumlah daun terbaik pada umur 30 HST sebesar 15,83 helai, sedangkan rerata hasil jumlah daun terendah terdapat pada perlakuan dosis vinasse 50.000 1/ha pada umur 30 HST sebesar 14,67 helai. Hal tersebut menunjukkan pada dosis vinasse $25.000 \mathrm{l} / \mathrm{ha}$ adalah dosis vinasse yang optimum untuk pak choi dan bunga kol. Diduga perlakuan pemberian dosis vinasse (V3) dapat memberikan keseimbangan hara dalam tanah sehingga mampu meningkatkan ketersediaan hara N, P dan K pada tanah. N, P dan K yang 
cukup akan meningkatkan laju fotosintesis yang akan mempengaruhi pertumbuhan vegetatif tanaman yang ditandai dengan peningkatan jumlah daun (Hasiholan et al., 2017).

Pengaruh Dosis POC Vinase Terhadap Hasil Tanaman Bunga Kol. Hasil analisis perlakuan POC vinasse terhadap variabel hasil tanaman bunga kol disajikan pada Tabel 3. Berdasarkan hasil sidik ragam menunjukkan bahwa perlakuan beberapa dosis pupuk organik cair vinasse berpengaruh sangat nyata terhadap bobot segar bunga per sampel, bobot segar bunga per bedeng dan bobot brangkasan per sampel.

Tabel 3. Rerata variabel hasil tanaman Bunga Kol

\begin{tabular}{lccc}
\hline & \multicolumn{3}{c}{ Variabel Hasil Tanaman } \\
\cline { 2 - 4 } Perlakuan & $\begin{array}{c}\text { Bobot Bunga } \\
\text { Per Sampel } \\
(\mathrm{g})\end{array}$ & $\begin{array}{c}\text { Bobot } \\
\text { Bunga Per } \\
\text { Bedeng } \\
(\mathrm{g})\end{array}$ & $\begin{array}{c}\text { Bobot } \\
\text { Brangkasan Segar } \\
\text { Per } \\
\text { Sampel }(\mathrm{g})\end{array}$ \\
\hline V0 : Tanpa Vinase 0 1/ha & $625,00 \mathrm{c}$ & $6700,00 \mathrm{~b}$ & $1213,33 \mathrm{~b}$ \\
V1 : Vinase 15.000 1/ha & $620,00 \mathrm{c}$ & $6750,00 \mathrm{~b}$ & $1335,00 \mathrm{~b}$ \\
V2 : Vinase 20.000 1/ha & $685,00 \mathrm{~b}$ & $7550,00 \mathrm{a}$ & $1290,00 \mathrm{~b}$ \\
V3 : Vinase 25.000 1/ha & $730,00 \mathrm{a}$ & $7870,00 \mathrm{a}$ & $1576,67 \mathrm{a}$ \\
\hline
\end{tabular}

Keterangan : Angka yang diikuti huruf yang berbeda pada kolom yang sama menunjukkan berbeda nyata menurut Uji BNT pada taraf $5 \%$.

Pengaruh pemberian vinasse terhadap hasil tanaman bunga kol, disajikan pada kurva respon (Gambar 2). Berdasarkan gambar tersebut menunjukkan bahwa semakin tinggi dosis pupuk vinasse yang diberikan maka semakin tinggi respon dari variabel hasil tanaman bunga kol. Pada perlakuan dosis vinasse (V3) memberikan hasil yang terbaik pada semua variabel hasil tanaman bunga kol. Hasil tersebut sesuai dengan potensi bobot tanaman pada deskripsi varietas yaitu sebesar >1000 g. Menurut Yulisma (2011), kemampuan tanaman untuk dapat tumbuh dan berkembang dengan optimal tidak hanya dipengaruhii oleh sifat genetik suatu varietas saja, namun juga dipengaruhi faktor lingkungan. Apriliani et al., (2016) menambahkan bahwa apabila suatu tanaman tercukupi kebutuhan lingkungannya khususnya dari segi unsur hara maka tanaman tersebut akan dapat mengekspresikan faktor genetiknya secara lengkap karena dapat menyelesaikan siklus hidupnya secara utuh sehingga mampu menampilkan potensi hasilnya. Berdasarkan variabel hasil tersebut diduga tanaman bunga kol mendapatkan unsur hara yang cukup, karena unsur hara tidak hanya diberikan melalui pupuk dasar, pupuk susulan dari NPK (16-16-16), tetapi juga pemberian pupuk vinasse sehingga kebutuhan nutrisi tanaman terpenuhi. Hasil tersebut sejalan dengan hasil penelitian Vyatrisa et al. (2017) tentang pengaruh vinasse dan macam pupuk organik terhadap pertumbuhan dan hasil pak choi, bahwa penggunaan dosis pupuk vinasse 25.000 1/ha memberikan hasil rerata bobot segar tajuk paling baik, sedangkan hasil rerata terendah pada perlakuan dosis vinasse 0 l/ha (kontrol). Hal tersebut menunjukkan vinasse berpotensi besar untuk dimanfaatkan sebagai pupuk organik, karena mengandung $2 \%$ kalium, $0,4 \%$ nitrogen dan 0,2\% fosfor (Maghfiroh et al., 2016; Lamuri et al., 2016). 

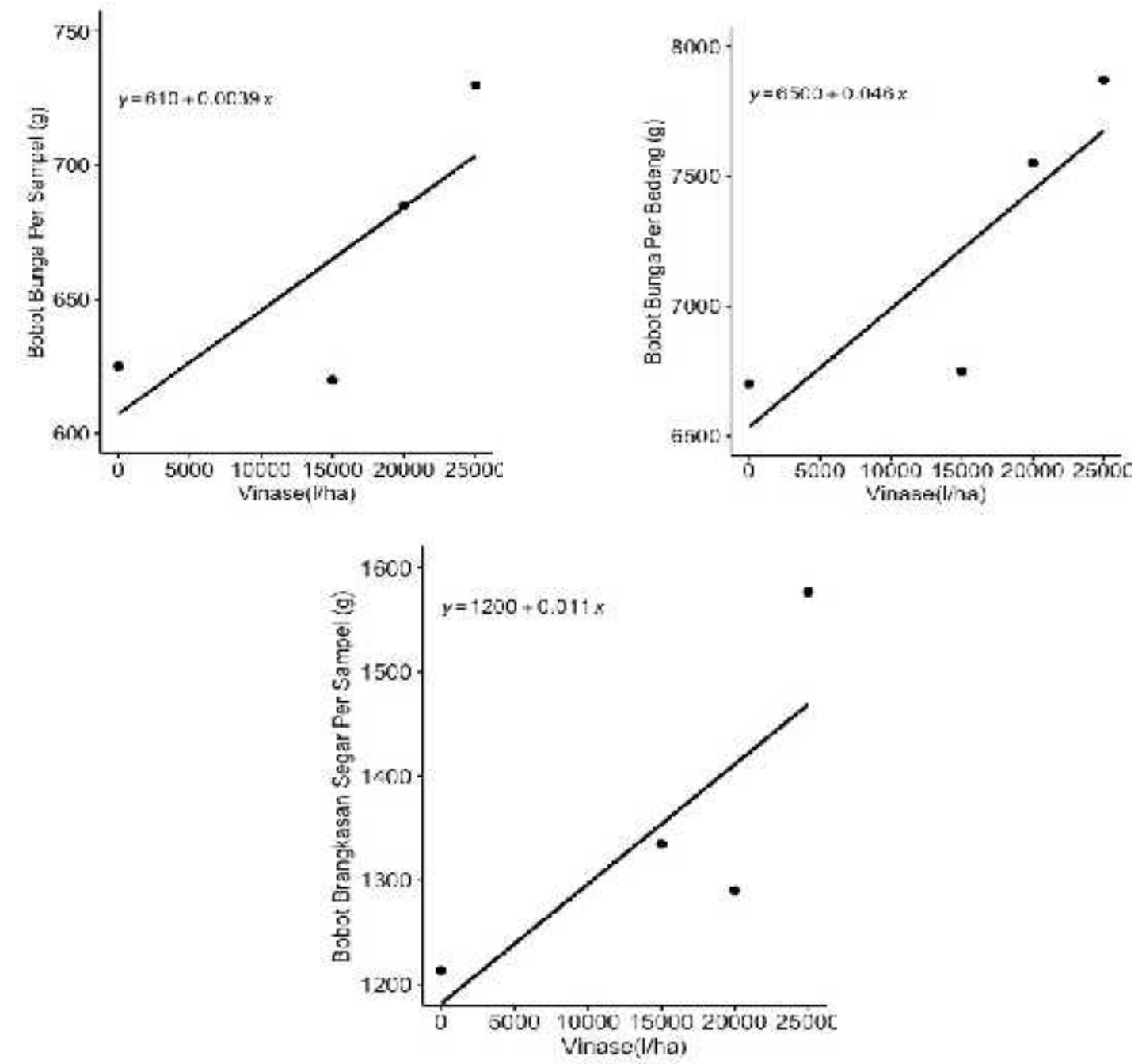

Gambar 2. Kurva respon pemberian vinasse terhadap komponen hasil tanaman bunga kol

\section{KESIMPULAN}

Pemberian beberapa macam dosis vinasse berpengaruh sangat nyata pada variabel tinggi tanaman umur 14 dan 21 HST, bobot segar bunga per sampel, bobot segar bunga per bedeng dan bobot segar brangkasan per sampel dan berpengaruh nyata pada variabel jumlah daun pada umur 14 dan 21 HST. Perlakuan terbaik terdapat pada perlakuan pemberian pupuk vinasse 25.000 1/ha (V3) pada semua variabel pengamatan pertumbuhan dan hasil bunga kol.

\section{DAFTAR PUSTAKA}

Apriliani, I., Heddy, S. \& Suminarti, N., 2016. Pengaruh kalium pada pertumbuhan dan hasil dua varietas tanaman ubi jalar (Ipomea batatas (L.) Lamb). Jurnal Produksi Tanaman, 4(4), pp. 264-270.

Badan Pusat Statistik Indonesia. 2018. Statistik Tanaman Sayuran dan Buah-Buahan Semusim 2018. Jakarta: BPS RI.

BPS Provinsi Jawa Timur. 2017. Produksi Sayuran dan Buah-buahan Semusim di Jawa Timur Tahun 20082017. Surabaya: BPS Jawa Timur.

Dewi, A. dan Simanjuntak, B., 2015. Aplikasi Berbagai Dekomposer pada Vinasse Terhadap Kualitas Pupuk Organik Cair, Pertumbuhan dan Hasil Tanaman Selada Hijau ( Lactuca sativa L .). Prosiding 
Ma'rufah, dkk : Pemanfaatan Vinasse sebagai Pupuk Organik Cair Untuk Meningkatkan.

Seminar Nasional Pangan Lokal, Bisnis dan Eko-Industri (hlm. 100-108).

Hasiholan, A., Armaini \& Yoseva, S., 2017. Pengaruh Perbedaan Dosis Limbah Cair Bioetanol (Vinasse) Terfermentasi Terhadap Pertumbuhan Bibit Tanaman Kakao (Theobroma cacao L.). JOM FAPERTA Universitas Riau, 4(2), pp. 1-15.

Juhriah, Suhadiyah, S., Muhtadin \& Lestari, D., 2018. Pemanfaatan Pupuk Organik Cair (Voc) Pada Budidaya Tanaman Kol Bunga Brassica oleraceae var. botrytis L.subvar. cauliflora. Jurnal Biologi Makasar, 3(1), pp. 35-47.

Lamuri, R. dan Maran, A. 2016. Pemanfaatan Limbah Cair Bioetanol Menjadi Pupuk Organik Cair (POC) (Skripsi). Fakultas Teknik, Universitas Katolik Widya Mandala.

Maghfiroh, C., Muhartini, S. \& Rogomulyo, R., 2016. Pengaruh Takaran dan Jenis Pupuk Hayati terhadap Pertumbuhan dan Hasil Sawi Hijau (Brassica rapa L . ) pada Sistem Pertanian Organik. Vegetalika, 5(4), pp. 15-24.

Qo'idah, N. 2015. Pengaruh Pemberian Bioaktivator Em4 Dan Ragi Tempe Pada Limbah Cair Tahu Terhadap Pertumbuhan Tanaman Tomat (Solanum lycopersicum l.) Var. Tymoti fl(Skripsi). Fakultas Ilmu Tarbiyah dan Keguruan, Universitas Islam Negeri Walisongo Semarang.

Sadewo, L. 2017. Potensi Pemanfaatan Vinasse Cair Sebagai Substitusi Pupuk Kalium Terhadap Pertumbuhan Dan Serapan K Pada Tanaman Tebu (Saccharum officinarum L.) (Tesis). Fakultas Pertanian, Universitas Brawijaya Malang.

Satriawi, W., Tini, E. \& Iqbal, A., 2015. Pengaruh Pemberian Pupuk Limbah Organik Terhadap Pertumbuhan Dan Hasil Tanaman Mentimun ( Cucumis Sativus L .). Jurnal Penelitian Pertanian Terapan, 19(2), pp. 116-121.

Sulaeman, Y., Maswar \& Erfandi, D., 2017. Pengaruh Kombinasi Pupuk Organik dan Anorganik Terhadap Sifat Kimia Tanah, dan Hasil Tanaman Jagung di Lahan Kering Masam. Jurnal Pengkajian dan Pengembangan Teknologi Pertanian, 20(1), pp. 1-12.

Umami, M., Waluyo, S., Muhartini, S. \& Rogomulyo, R., 2014. Pengaruh Residu Pemberian Vinasse Dan Pupuk Kalium Terhadap Pertumbuhan Dan Hasil Kangkung Darat (Ipomoea reptans Poir.)., Vegetalika, 3(1), pp. 12-21.

Vyatrisa, B., Muhartini, S. \& Waluyo, S., 2017. Pengaruh Vinase dan Macam Pupuk Organik terhadap Pertumbuhan dan Hasil Pak Choi ( Brassica rapa subsp. chinensis (L.) Hanelt). Vegetalika, 6(1), pp. $12-21$.

Wahyunindyawati, F., Kasijadi \& Abu. 2012. Pengaruh Pemberian Pupuk Organik Biogreen Granul terhadap Pertumbuhan dan Hasil Tanaman Bawang Merah. Journal Basic Science and Technology. (1), pp. $21-25$

Yulisma. 2011. Pertumbuhan dan Hasil Beberapa Varietas Jagung pada Berbagai Jarak Tanam. Penelitian Pertanian Tanaman Pangan, 30(3), pp. 196-203. 